\title{
Doppler Ultrasound of Hepatic Artery and Portal Vein: Relationship with Clinical Severity of Hepatitis C Virus Liver Cirrhosis
}

\author{
MEDHAT I.M. AHMAD, M.D. \\ The Department of Radiology, Sohag University Hospital, Sohag, Egypt
}

\begin{abstract}
Background: Doppler ultrasonography is an essential part of evaluating the vascular haemodynamic variation seen within cirrhotic patients. Differences in haemodynamics exhibited in hepatic vasculature has been appeared in previous reports to associate with the clinical severity of cirrhosis. In any case, the degree of changes in Doppler ultrasound flow parameters in foreseeing the clinical severity of liver cirrhosis stays uncertain.
\end{abstract}

Aim of Study: The purpose of this study was to evaluate the contribution of Doppler ultrasound of Hepatic Artery (HA) and Portal Vein (PV) with Child-Pugh (CP) score to assess the advancement of Hepatitis C Virus (HCV)-related liver cirrhosis

Patients and Methods: One hundred patients with HCVrelated liver cirrhosis divided according to $\mathrm{CP}$ score were included. Doppler ultrasound variables including Portal Vein (PV) diameter, Maximum Portal Vein Velocity (MPVV), and resistance index of the hepatic artery (HARI) were measured.

Results: There was significant association between the diameter of PV and the increase in CP score, which was statistically significant $(p=0.000)$. A choice of $12 \mathrm{~mm}$ as a cutoff point of $\mathrm{PV}$ diameter between $\mathrm{CP}, \mathrm{A}$ and $\mathrm{B}$ revealed sensitivity of $96.9 \%$, and specificity of $97.9 \%$. The mean MPVV was statistically significantly higher with Child A (mean $17.1 \pm 1.6 \mathrm{~cm} / \mathrm{sec})$, compared to Child B and $\mathrm{C}(\mathrm{p}=$ $0.000)$, and Child B (mean $14.1 \pm 1.9 \mathrm{~cm} / \mathrm{sec}$ ) compared to Child C (mean $11.3 \pm 1.4 \mathrm{~cm} / \mathrm{sec})(p=0.000)$. The mean HARI was statistically significantly lower with Child A and B $(0.8 \mathrm{~cm} / \mathrm{sec})$, compared to Child C $(0.9 \mathrm{~cm} / \mathrm{sec})(p=0.000)$. There was a strong negative correlation between HARI and MPVV which was statistically significant $(p=0.000)$. There was a strong positive correlation between HARI and Child class and diameter of PV which was statistically significant $(p=0.000)$.

Conclusion: PV diameter is a useful predictor of advancement of liver cirrhosis. Doppler measurements of MPVV, and HARI are useful in differentiating patients with $\mathrm{CP}, \mathrm{A}$ and $\mathrm{B}$ from C.

Key Words: Hepatic Artery (HA) - Portal Vein (PV) - ChildPugh $(\mathrm{CP})$ - Hepatitis C Virus $(\mathrm{HCV})$ - Related liver cirrhosis.

Correspondence to: Dr. Medhat I.M. Ahmad, E-Mail: mandw20022002@hotmail.com

\section{Introduction}

THE liver cirrhosis serve as the eventual phase of a mixture of chronic liver disease of various causes including that caused by Hepatitis C Virus (HCV) [1]. The liver is in permanent remodeling to fibrosis with the development of regeneration nodules [2]

The destruction of the lobule and vascular structure leads to liver failure and the associated complications such as, formation of intrahepatic shunts, portal hypertension, haemorrhagic diathesis, ascites, variceal bleeding, spontaneous bacterial peritonitis, hepatic encephalopathy and liver failure coma [2]

Clinical severity of liver cirrhosis can be easily predicted and grouped by $\mathrm{CP}$ score. The $\mathrm{CP}$ score is figured using five clinical measures of liver disease; total bilirubin, albumin, prothrombin time or INR, ascites, and encephalopathy. CP score has been shown helpful in determining prognosis of patients with chronic liver disease and also response to treatment and necessity for transplant [3] .

Different studies have shown the profit of significant measurements in the contribution of Doppler ultrasound with Child-Pugh (CP) score to estimate the advancement of Hepatitis $\mathrm{C}$ Virus (HCV)-related liver cirrhosis [4,5].

Various Doppler parameters, such as Maximum Velocity in Portal Vein (MPVV), Hepatic Artery Resistive Index (HARI) (peak systolic velocityend diastolic velocity)/peak systolic velocity and diameter of portal vein were used [6]

A significant reduction in portal vein velocity and flow and a significant rise in HARI have been frequently described in advanced cirrhotic patients $[7,8]$.

On other side, the results of different studies do not match in term of usability of Doppler meas- 
urement for determination of stage of liver cirrhosis and be controversial among experts [9]

However, the extent of changes in Doppler US flow parameters in predicting the severity of liver cirrhosis remains unclear.

The current study was primarily described to evaluate the contribution of Doppler ultrasound of Hepatic Artery (HA) and Portal Vein (PV) with Child-Pugh score to assess the advancement of HCV-related liver cirrhosis.

\section{Patients and Methods}

Study design:

It was a cross-sectional study carried out from January 2016 to November 2018. The study was carried out in Department of Radiology, Sohag University hospital, Egypt.

\section{Patients:}

A total of 100 patients with HCV-related liver cirrhosis constituted the study groups. Diagnosis of liver cirrhosis was based on combination of clinical data, laboratory data and ultrasound data and carried out in Department of Internal Medicine, Sohag University Hospital, Egypt.

The patients were grouped according to the Child Pugh classification. Child Pugh Score is calculated based on total bilirubin, serum albumin, prothrombin time, ascites and encephalopathy.

\section{Equipment:}

All Doppler ultrasound examinations was performed and interpreted by one investigator according to standard protocol using Aplio 500 Platinum ultrasound unit (Toshiba Medical Systems, Tokyo, Japan), with multifrequency $3.5 \mathrm{MHz}$ convex transducer.

\section{Doppler measurements:}

The following hemodynamic parameters were measured on the portal, and hepatic circulation:

1- Maximum velocity of the main portal vein (MPVV) $(\mathrm{cm} / \mathrm{s})$ was measured in its mid-portion, where the Hepatic Artery (HA) crosses the portal vein, on oblique subcostal scans. The axial size of the sample volume was adjusted to encompass the portal vein lumen in its entirety. The angle between the Doppler beam and the long axis of the vessel was made to be $<60^{\circ}$. MPVV was automatically calculated on samples of the Doppler signal lasting more than 3 seconds.

2- The Hepatic Artery Resistive Index (HARI) was measured on the proper HA, at its crossing of the portal vein, by using a Doppler sample length of 3 to $9 \mathrm{~mm}$. The peak systolic (S) and peak end-diastolic (D) Doppler frequency shifts were measured manually on the time-frequency Doppler spectrum by calipers, and the RI was automatically calculated as RI 5 (S-D)/S.

3- The diameter of the portal vein (in mm) was measured in longitudinal section, at the exact site of the Doppler sample volume.

Statistical analysis:

Statistical analysis was performed using SPSS 17.0 (SPSS Inc., Chicago, IL, USA). Numerical variables are expressed as mean \pm standard deviation and categorical variables as percent $(\%)$. Correlations between MPPV, diameter of the portal vein, and HARI were evaluated by Spearman correlation test. Statistical analyses of differences between the groups were made with one-way Analysis of Variance (ANOVA). Student's $t$-test was used for comparison of quantitative parameters between two groups, and the $\chi$ test with Yates' correction for comparison of qualitative variables. The Area Under the Curve (AUC) from a receiver operating characteristic curve analysis of Doppler parameters for predicating the Child-Pugh classification were calculated. Results were considered significant when $p$ was $<0.05$.

\section{Results}

The study group consisted of 100 cirrhotic patients; 64 male and 36 female. The mean age was $60.9 \pm 7.7$ years. The status of liver cirrhosis was evaluated clinically by score of Child-Pugh.

Forty eight patients with Child A, 32 Child B, and 20 with Child C. About 16 (70\%) of Child C were male. Demographic data, Doppler ultrasound findings and Child Pugh score in study group in relation to different stages of liver cirrhosis, shown in Table (1). The distribution of MPVV, HARI and PV diameter values by Child class groups shown in Figs. $(1,2,3)$.

\section{Portal vein:}

The mean diameter of PV was $12.13 \pm 2.5 \mathrm{~mm}$ (range $7-16 \mathrm{~mm}$ ). The mean diameters of PV in Child A was $9.8 \pm 1.3 \mathrm{~mm}$. The mean diameters of $\mathrm{PV}$ in Child B and C was $14.1 \pm 0.8$ and $14.6 \pm 0.7 \mathrm{~mm}$ respectively.

There was a statistically significant differences between Child groups as determined by one-way ANOVA $(p=0.000)$. A Tukey post hoc test revealed that the mean diameter of PV was statistically significantly lower with Child A ( $p=0.000)$, compared to Child B and C. There was no statistically significant difference between the Child B and C 
groups ( $p=0.26$ ). The distribution of PV diameter values by Child class groups shown in Fig. (1).

The performance of PV diameter for differentiating Child A from Child B using receiver operating characteristic curve (ROC) and selection of $12 \mathrm{~mm}$ as a cutoff point of $\mathrm{PV}$ diameter revealed Area Under Curve (AUC) of 0.99, sensitivity of $96.9 \%$, and specificity of $97.9 \%$, see Fig. (2).

There was a strong positive correlation between PV diameter and Child Pugh which was statistically significant $(p=0.000)$.

The mean maximum velocity of PV (MPVV) was $14.9 \pm 2.8 \mathrm{~cm} / \mathrm{sec}$. There was statistically significant differences between Child groups $(p=$ 0.000). The mean MPVV was statistically significantly higher with Child A (mean $17.1 \pm 1.6 \mathrm{~cm} / \mathrm{sec}$ \& range $12.5-19.4 \mathrm{~cm} / \mathrm{sec}$ ), compared to Child $\mathrm{B}$ and C $(p=0.000)$, and Child B (mean 14.1 \pm 1.9 $\mathrm{cm} / \mathrm{sec} \&$ range $11.5-17.6 \mathrm{~cm} / \mathrm{sec}$ ) compared to Child C (mean $11.3 \pm 1.4 \mathrm{~cm} / \mathrm{sec} \&$ range $9.5-13.4$ $\mathrm{cm} / \mathrm{sec})(p=0.000)$ see Figs. $(3,4)$.

ROC curve shows the performance of MPVV for differentiating Child A from Child B, see Fig. (3). Selection of $16.1 \mathrm{~cm} / \mathrm{sec}$ as a cutoff point of MPVV value revealed AUC of 0.88 , sensitivity of $87.5 \%$, and specificity of $79.2 \%$ see Fig. (5).

ROC curve shows the performance of MPVV for differentiating Child B from Child C. Selection of $11.6 \mathrm{~cm} / \mathrm{sec}$ as a cutoff point of MPVV value revealed AUC of 0.88 , sensitivity of $70 \%$, and specificity of $87.5 \%$, see figure 6 . There was a strong negative correlation between PV diameter and MPVV which was statistically significant $(p=0.000)$. The reverse of flow was found in 5 patients $(20 \%)$ of Child C with average mean velocity $-12.2 \pm 2.3 \mathrm{~cm} / \mathrm{sec}$.

\section{Hepatic artery:}

The mean of HARI was $0.7 \pm 0.1 \mathrm{~cm} / \mathrm{sec}$ (rang 0.7-0.9). The mean of HARI was relatively equal in Child A and Child B $(0.8 \mathrm{~cm} / \mathrm{sec})$ but lower than Child C $(0.9 \mathrm{~cm} / \mathrm{sec})$, see Fig. (7).

There was a statistically significant differences between HARI of Child A and C and Child B and C, as determined by one-way ANOVA $(p=0.000)$. A Tukey post hoc test revealed that the mean HARI was statistically significantly lower with Child A and B, compared to Child C ( $p=0.000)$, see Figs. $(8,9)$.

ROC curve shows the performance of HARI for differentiating Child B from Child C, see Fig. (5). Selection of $>0.86$ as a cutoff point of HARI value revealed Area Under Curve (AUC) of 0.88 , sensitivity of $70 \%$, and specificity of $93.7 \%$, see Fig. (10).

There was a strong negative correlation between HARI and MPVV which was statistically significant $(p=0.000)$. There was a strong, positive correlation between HARI and Child class and diameter of PV which was statistically significant $(p=0.000)$.

Table (1): Basic demographic data, Doppler ultrasound findings and Child Pugh score in study group in relation to different stages of liver cirrhosis.

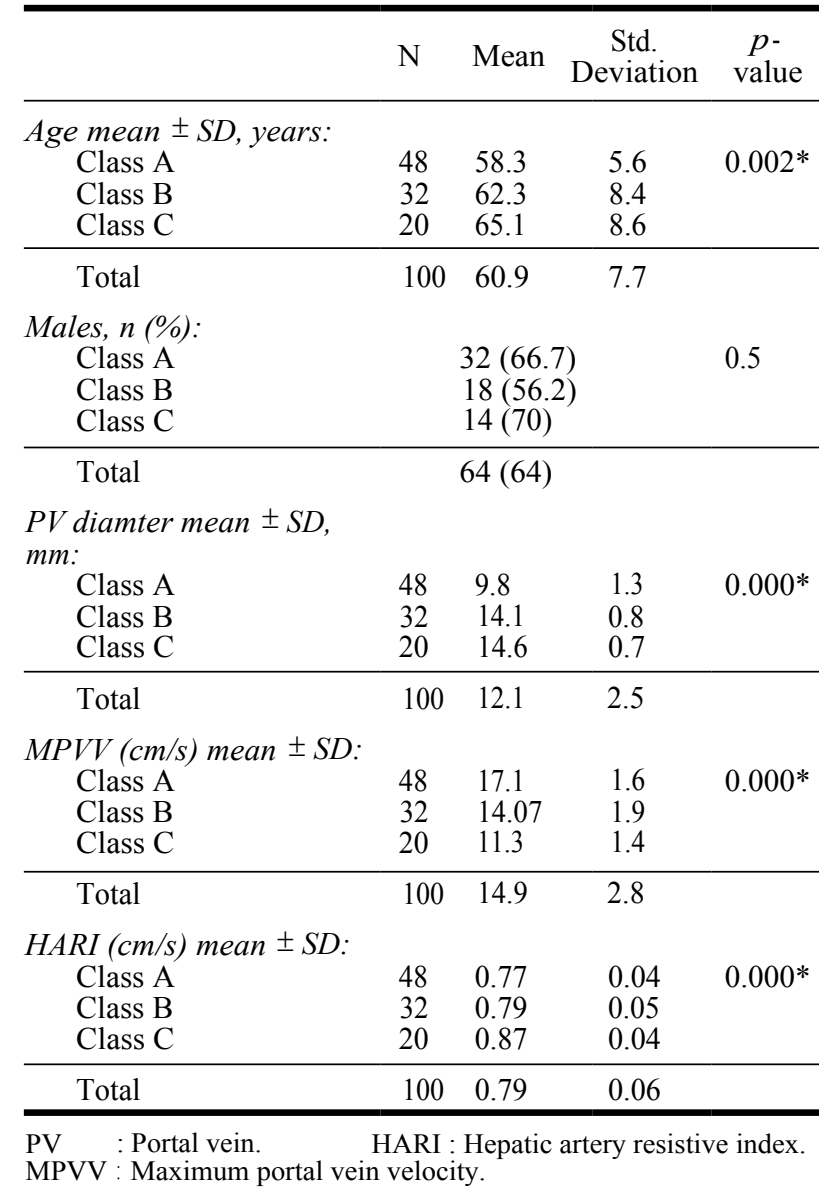

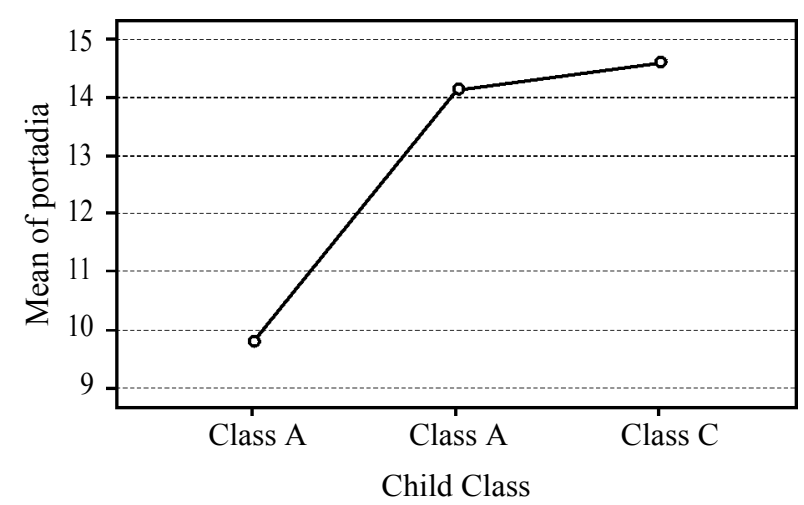

Fig. (1): Distribution of PV diameter values by Child class groups. The mean diameter of PV was lower with Child A, compared to Child B and C. 


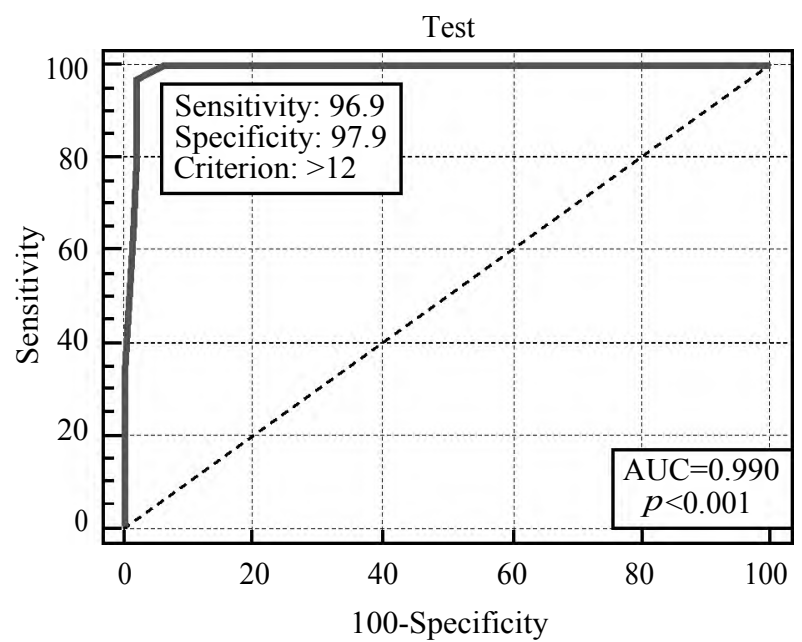

Fig. (2): ROC curve shows the performance of PV diameter for differentiating Child A from Child B (Selection of $12 \mathrm{~mm}$ as a cutoff point of PV diameter revealed AUC of 0.99 , sensitivity of $96.9 \%$, and specificity of $97.9 \%$.

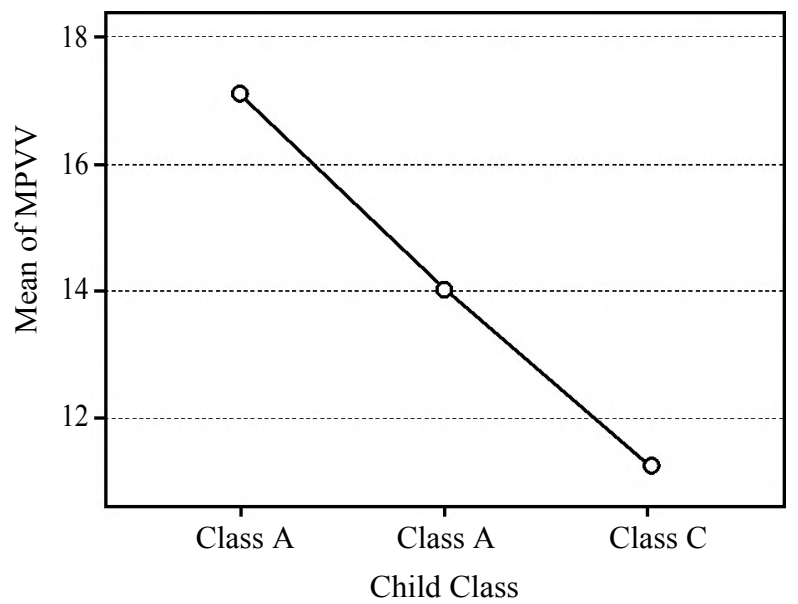

Fig. (3): Distribution of MPVV values by Child class groups. The mean MPVV was higher with Child A, compared to Child $\mathrm{B}$ and $\mathrm{C}$.
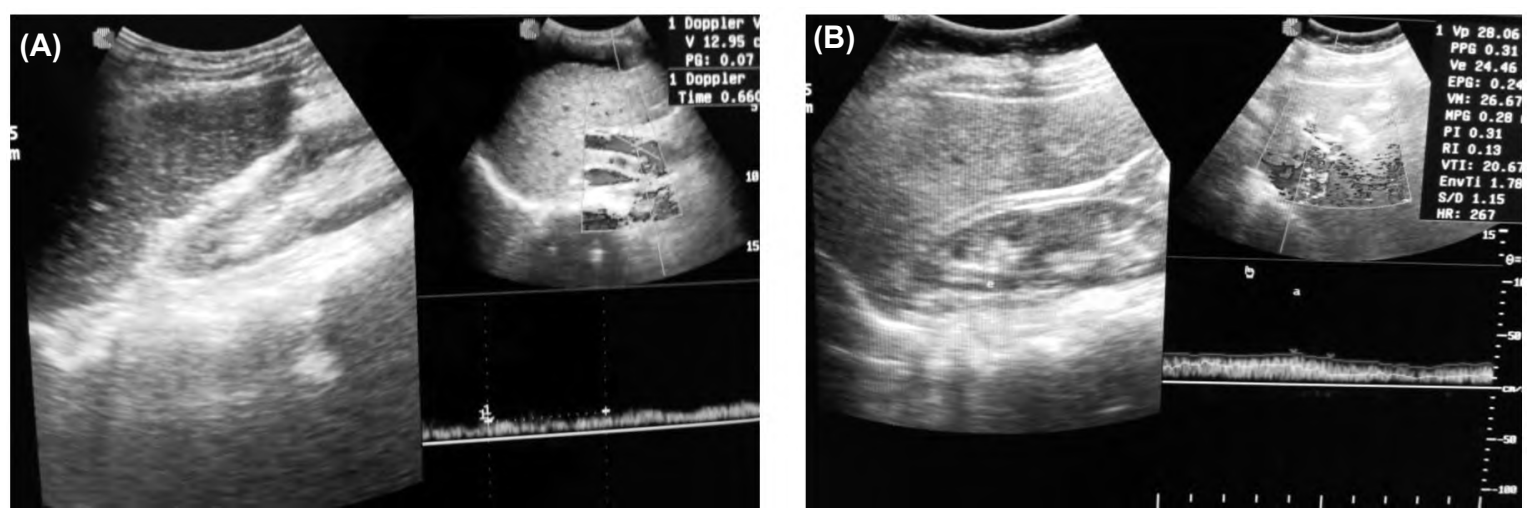

Fig. (4): Spectral dropper ultrasound pictures showing maximum peak velocity of $28 \mathrm{~cm} / \mathrm{s}$, and $12 \mathrm{~cm} / \mathrm{sec}$ in the portal vein of cirrhotic patients with CP Grade 1 (A), and Grade 3 (B) respectively.

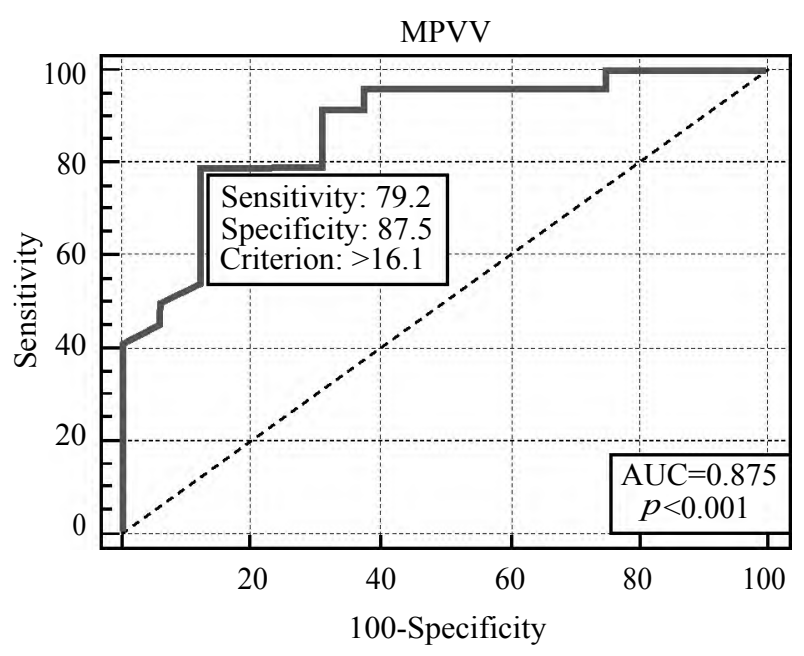

Fig. (5): ROC curve shows the performance of MPVV for differentiating Child A from Child B (Selection of $16.1 \mathrm{~cm} / \mathrm{sec}$ as a cutoff point of MPVV revealed AUC of 0.88 , sensitivity of $79.2 \%$, and specificity of $87.5 \%$.

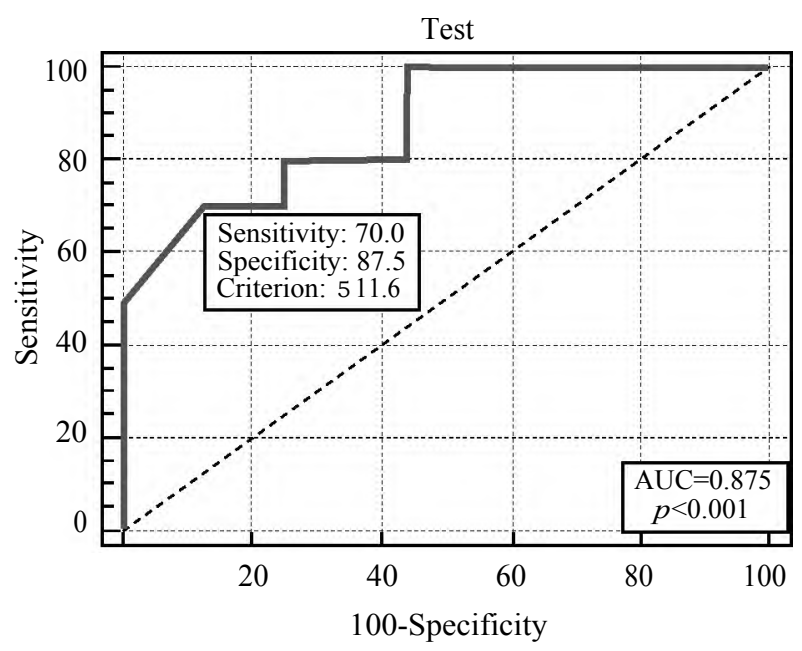

Fig. (6): ROC curve shows the performance of MPVV for differentiating Child B from Child C (Selection of $11.6 \mathrm{~cm} / \mathrm{sec}$ as a cutoff point of MPVV revealed AUC of 0.88 , sensitivity of $70 \%$, and specificity of $87.5 \%$. 


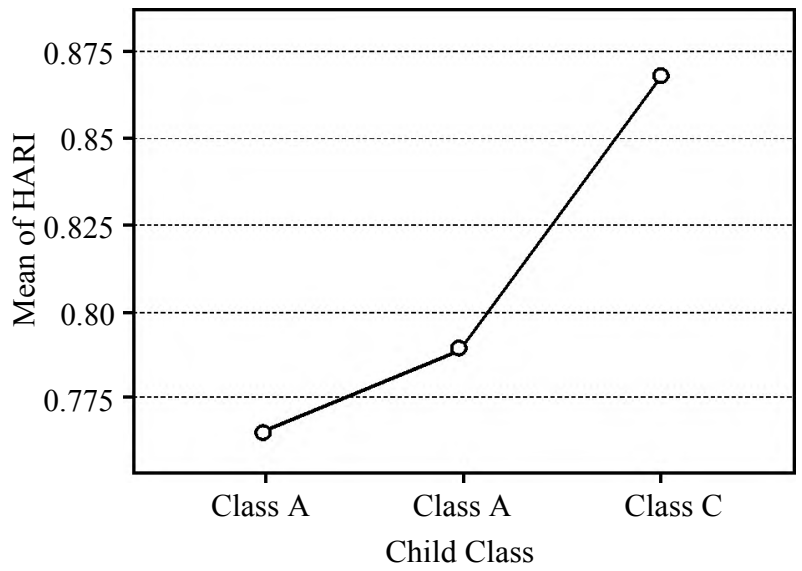

Fig. (7): Distribution of HARI values by Child class groups. The mean of HARI was relatively equal in Child A and Child B, but lower than Child C.

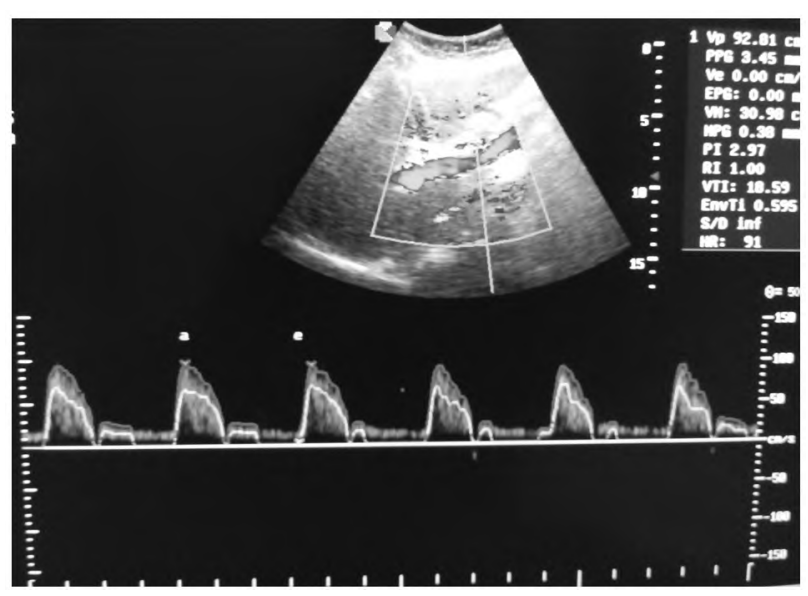

Fig. (9): Automated Doppler tracing of the HA waveform in 60-year old male cirrhotic patient with CP score C, shows a spectrum of abnormal high arterial resistance $(\mathrm{RI}=1)$.

\section{Discussion}

In the current study we determined to compare PV diameter, MPVV, and HARI, as handily applicable Doppler ultrasound values with Child Pugh score, a clinical and biochemical parameter that is used to assess the prognosis of liver cirrhosis and which is question of various researches.

We arranged the strength on these parameters for assessing the stage of liver cirrhosis, which we have accepted with the research data.

In the present study, a choice of $12 \mathrm{~mm}$ as a cutoff point of PV diameter between Child Pugh $A$ and $B$ revealed sensitivity of $96.9 \%$, and specificity of $97.9 \%$. Thus, it is easy to assume that the

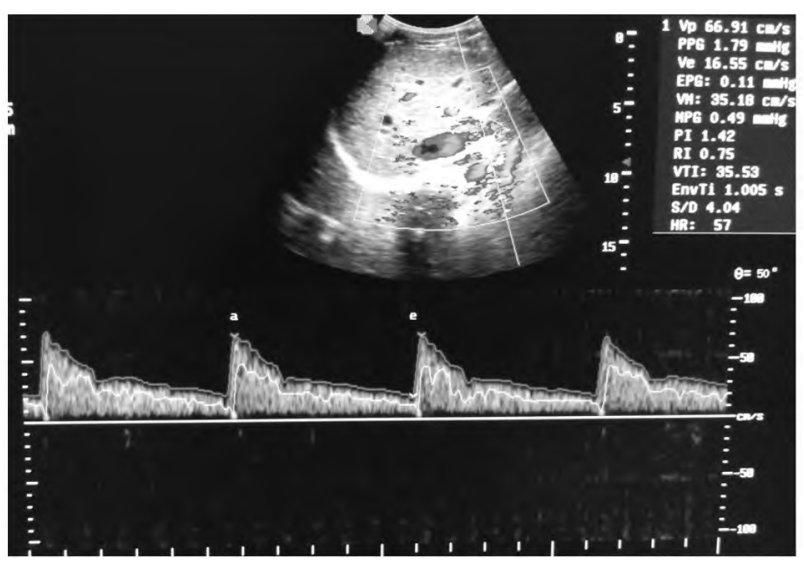

Fig. (8): Automated Doppler tracing of the HA waveform in 45-year old male cirrhotic patient with CP score A, shows a spectrum of normal low arterial resistance $(\mathrm{RI}=0.7)$.

HARI

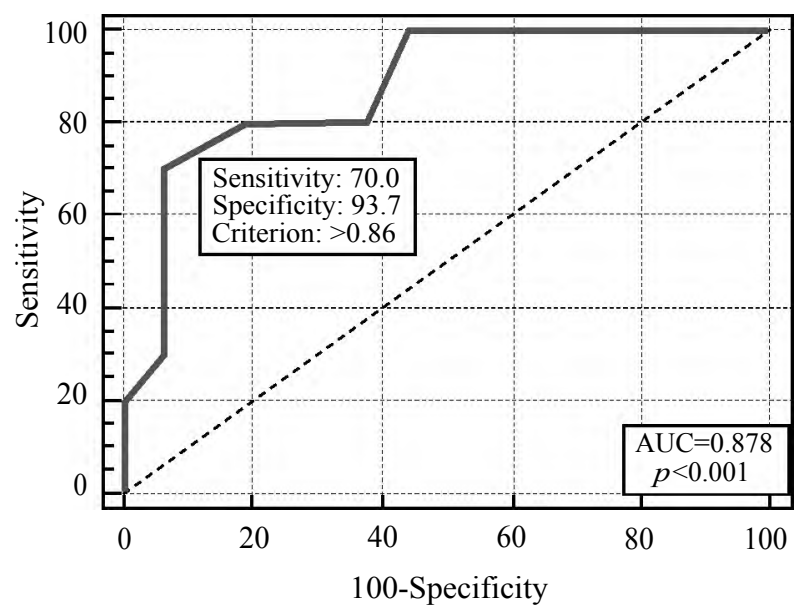

Fig. (10): ROC curve shows the performance of HARI for differentiating Child B from Child C (Selection of $>0.86 \mathrm{~cm} / \mathrm{sec}$ as a cutoff point of HARI value revealed AUC of 0.88 , sensitivity of $70 \%$, and specificity of $93.7 \%$.

PV diameter by more than $12 \mathrm{~cm}$ can be a sign of aggressiveness of cirrhosis.

Kamran et al., showed that the diameter of PV more than $13 \mathrm{~cm}$ may be considered as a sign of portal hypertension [5]. Another study by Macias selected $12 \mathrm{~mm}$ as a cutoff point for diagnosis of cirrhosis [10].

In contrast, we find some studies that prove the lack of an effective relationship between the diameter of PV and portal hypertension [5], or even cirrhosis [11].

The relationship between the diameter of PV and the severity of HCV-related liver cirrhosis has been studied in many reports and despite the dif- 
ferences, but each of them reflects the reality and the circumstances of different studies forcing us to search for a local formula of the results.

In the present study, MPVV diminished with the advancement of liver cirrhosis. These results are consistent with El-Shabrawi et al., who observed that PV veolcity correlate with the severity of liver cirrhosis [6]. Also, Zecanovic et al., demonstrated inverse relationship between the grade of liver cirrhosis and PV velocity [12]. Kayacetin et al., reported that velocity of PV was reduced in Child Pugh C [13] . Our results and the previous studies agree with the fact that fibrous tissue bands separate hepatocyte nodules, which eventually replace the entire liver architecture, in process of cirrhosis leading to decreased blood flow throughout.

The current study observed that Child Pugh C had statistically significantly high HARI. Also, with selection of $>0.86$ as a cutoff point of HARI help in differentiating Child Pugh B from C. These results agree with "hepatic arterial buffer response theory," where to keep the blood flow to cirrhotic liver, the resistance of artery should be inversely proportional to portal venous flow $[\mathbf{1 4 , 1 5}$.

We additionally checked the correlation between PV diameter and the Child Pugh class, MPVV, and HARI. We observed a strong positive correlation between PV diameter and Child Pugh class and HARI. In contrast, we found a strong negative correlation between PV diameter and MPVV. These findings follow the results of previous studies $[16,17]$, and clarify the association between the clinical staging of severity of cirrhosis and PV diameter.

We found a strong negative correlation between HARI and MPVV, which means that the lower the amount of blood received by PV the high in arterial resistance in HA.

The liver receives about 75 percent of the blood through the PV. In the case of cirrhosis, there is a severe shortage of blood supply, which results in a decrease in the quantity and velocity of the blood reaching through the PV. In order to avoid the lack of oxygen supply to the liver is compensated by the balance of increased resistance in the HA, which in turn leads to an increase in the amount of blood reaching the liver [18].

Previous studies demonstrated a significant reduction in flow volume and velocity of PV associated with increase severity of liver cirrhosis $[\mathbf{8 , 1 8}]$
This study revealed that combining clinical scoring system as Child Pugh with Doppler ultrasound work as an easy, simple, inexpensive and accomplished tool to arrive at a logical assessment of the regional liver cirrhosis and can facilitate the discovery of new pharmacological methods to deal with patients.

\section{Conclusion:}

There are significant hemodynamic difference found in the PV and the HA in patients with hepatitis $C$ virus liver cirrhosis, these changes correlated with the grading of the clinical severity of the cirrhosis. There was a strong positive correlation between PV diameter and Child Pugh class. MPVV was s essentially lower with Child C suggesting a reduced portal flow while the HARI was observed to be significantly higher in Child $\mathrm{C}$ proposing an increased hepatic artery blood flow.

\section{References}

1- KHULLAR V. and FIRPI R.J.: Hepatitis C cirrhosis: New perspectives for diagnosis and treatment. World J. Hepatol., 7 (14): 1843-55, 2015.

2- YEOM S.K., LEE C.H., CHA S.H. and PARK C.M.: Prediction of liver cirrhosis, using diagnostic imaging tools. World J. Hepatol., 7 (17): 2069-79, 2015.

3- SICILIANO M., PARLATI L., MALDARELLI F., ROSSI M. and GINANNI CORRADINI S.: Liver transplantation in adults: Choosing the appropriate timing. World $\mathrm{J}$. Gastrointest. Pharmacol. Ther., 3 (4): 49-61, 2012.

4- AFIF A.M., CHANG J.P., WANG Y.Y., et al.: A sonographic Doppler study of the hepatic vein, portal vein and hepatic artery in liver cirrhosis: Correlation of hepatic hemodynamics with clinical Child Pugh score in Singapore. Ultrasound, 25 (4): 213-21, 2017.

5- KAMRAN SHATERIA, AFSHIN MOHAMMADIB, FARZAD MOLOUDIC, et al.: Correlation Between Sonographic Portal Vein Diameter and Flow Velocity With the Clinical Scoring Systems MELD and CTP in Cirrhotic Patients: Is There a Relationship. Gastroenterology Research, 5 (3): 112-9, 2012.

6- EL-SHABRAWI M.H., EL-RAZIKY M., SHEIBA M., EL-KARAKSY H.M., et al.: Value of duplex Doppler ultrasonography in non-invasive assessment of children with chronic liver disease. World J. Gastroenterol., 16 (48): 6139-44, 2010.

7- TANA C., TANA M., ROSSI S., SILINGARDI M. and SCHIAVONE C.: Hepatic artery resistive index (HARI) and non-alcoholic fatty liver disease (NAFLD) fibrosis score in NAFLD patients: Cut-off suggestive of nonalcoholic steatohepatitis (NASH) evolution. J. Ultrasound. Mar., 29; 19 (3): 183-9, 2016

8- YAN G., DUAN Y., RUAN L., CHAO T. and YANG Y.: A study on the relationship between ultrasonographic score and clinical score (MELD, CPT) in cirrhosis. Hepatogastroenterology, 52 (65): 1329-33, 2005. 
9- COSAR S., OKTAR S.O., COSAR B., YÜCEL C. and OZDEMIR H.: Doppler and gray-scale ultrasound evaluation of morphological and hemodynamic changes in liver vascualture in alcoholic patients. Eur. J. Radiol., 54 (3): 393-9, 2005.

10- MACIAS RODRIGUEZ M.A., RENDON UNCETA P., NAVAS RE LINQUE C., et al.: Ultrasonography in patients with chronic liver disease: Its usefulness in the diagnosis of cirrhosis. Rev. Esp. Enferm. Dig., 95 (4): 258-64, 251-7, 2003.

11- De BEM R.S., LORA F.L., De SOUZA R.C., et al.: Correlation of Doppler ultrasound of the portal system with endoscopic changes caused by portal hypertension in cirrhotic patients]. Arq. Gastroenterol., 43 (3): 178-83, 2006.

12-ZEKANOVIC D., LJUBICIC N., BOBAN M., NIKOLIC M., et al.: Doppler ultrasound of hepatic and system hemodynamics in patients with alcoholic liver cirrhosis. Dig. Dis. Sci., 55 (2): 458-66, 2010.

13- KAYACETIN E., EFE D. and DO GAN C.: Portal and splenic hemodynamics in cirrhotic patients: Relationship between esophageal variceal bleeding and the severity of hepatic failure. J. Gastroenterol., 39 (7): 661-7, 2004.

14- Portal and Splenic Hemodynamics in Cirrhotic Patients: relationship between esophageal variceal bleeding and the severity of hepatic failure. Kayacetin E., Efe D., Dog an C.J. Gastroenterol. Jul., 39 (7): 661-7, 2004.

15- YAN G., DUAN Y., RUAN L., CHAO T. and YANG Y.: A study on the relationship between ultrasonographic score and clinical score (MELD, CPT) in cirrhosis. Hepatogastroenterology, 52 (65): 1329-33, 2005.

16- Value of portal hemodynamics and hypersplenism in cirrhosis staging. Shi B.M., Wang X.Y., Mu Q.L., Wu T.H., Xu J. World J. Gastroenterol. Feb., 7; 11 (5): 70811, 2005.

17- NUSRAT S., KHAN M.S., FAZILI J. and MADHOUN M.F.: Cirrhosis and its complications: Evidence based treatment. World J. Gastroenterol., 20 (18): 5442-60, 2014.

18- ONG T.Z. and TAN H.J.: Ultrasonography is not reliable in diagnosing liver cirrhosis in clinical practice. Singapore Med. J., 44 (6): 293-5, 2003.

\section{دوبلر الموجات فوق الصوتية للشريان الكبدى الوريد البابى؛

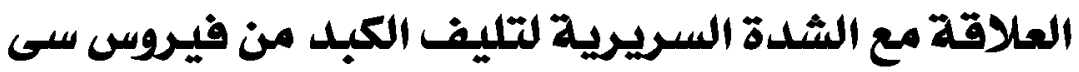

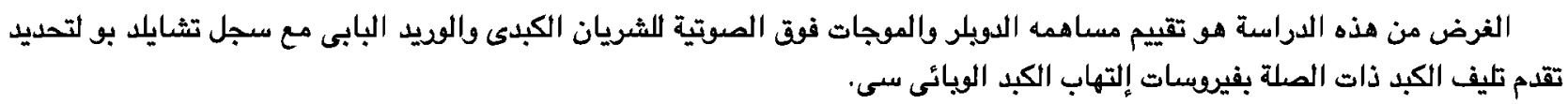

شملت الدراسة مائة مريض يعانون من تليف الكبد ذات الصلة بفيروس سى مقسمين وفقاً لدرجة سجل تشايلد بو وتم قياس متفيرات

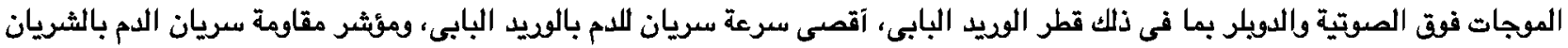

$$
\text { ومكن نتائج هذه الدراسة آنه تم الكشف عن إختبار بامم كنقطة قطع قطر الوديد البابى بين المجموعة آ وب طبقاً لسجل تشايلد بو. }
$$

وكان متوسط مؤثر مقاومة سريان الدم بالشريان الكبدى آقل بكثير من الناحية الإحصائية مع المجموعة آ وب، مقارنة بالمجموعة ج.

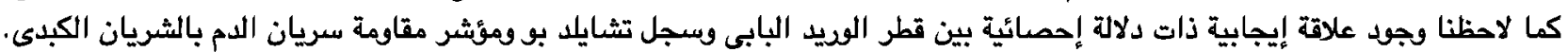

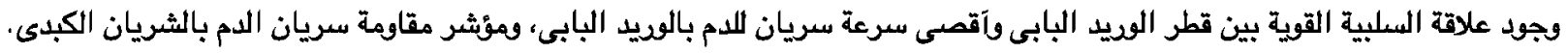

